\title{
Analisis Faktor Pelemahan Neutron dari Berbagai Jenis Bahan untuk Aplikasi Moderator/Reflektor dan Batang Kendali Pada Reaktor Termal
}

\author{
Mulya Prasetya*, Mohammad Ali Shafii \\ Laboratorium Fisika Nuklir, Jurusan Fisika, FMIPA, Universitas Andalas \\ Kampus Unand, Limau Manis, Padang, 25163 \\ *mulya.izanagi@gmail.com
}

\begin{abstract}
ABSTRAK
Salah satu cara untuk menentukan sifat moderator dalam reaktor termal dari berbagai bahan adalah dengan menganalisis faktor pelemahan neutronnya. Analisis faktor pelemahan neutron dilakukan pada beberapa jenis bahan berbentuk slab satu dimensi. Penelitian ini bertujuan untuk mengetahui sifat bahan yang cocok sebagai moderator dalam reaktor termal. Selain itu diperlihatkan juga bahan yang cocok sebagai batang kendali dan reflektor. Biasanya sifat-sifat bahan tersebut ditentukan berdasarkan data tampang lintang serapan dan hamburannya, namun dalam penelitian ini ditunjukkan bentuk pola pelemahan neutronnya. Penelitian ini dilakukan secara simulasi komputasi yang menampilkan pola faktor pelemahan neutron dengan menggunakan software MATLAB. Ketebalan bahan yang digunakan dalam penelitian ini adalah $20 \mathrm{~cm}$. Terdapat sepuluh bahan yang diteliti, yaitu air ringan $\left(\mathrm{H}_{2} \mathrm{O}\right)$, air berat $\left(\mathrm{D}_{2} \mathrm{O}\right)$, grafit $(\mathrm{C})$, berrilium $(\mathrm{Be})$, boron $(\mathrm{B})$, hidrogen $(\mathrm{H})$, helium $(\mathrm{He})$, natrium $(\mathrm{Na})$, besi $(\mathrm{Fe})$ dan deuterium (D). Data penampang lintang bahan yang digunakan dalam penelitian ini adalah data penampang lintang total bahan yang merupakan penjumlahan dari nilai penampang lintang serapan dan penampang lintang hamburan. Hasil penelitian menunjukkan bahwa berdasarkan pola faktor pelemahan neutronya bahan yang cocok sebagai moderator dan juga reflector adalah air ringan $\left(\mathrm{H}_{2} \mathrm{O}\right)$, air berat $\left(\mathrm{D}_{2} \mathrm{O}\right)$, grafit $(\mathrm{C})$ dan berrilium $(\mathrm{Be})$. Selain itu, pada penelitian ini diperoleh bahan yang cocok sebagai batang kendali adalah boron (B).

Kata kunci: Faktor pelemahan neutron, moderator, reaktor termal, penampang lintang total
\end{abstract}

\section{ABSTRACT}

One of ways to determine the properties of a moderator in a thermal reactor of various materials is to analyze the attenuation factor of its neutrons. The analysis of neutron attenuation factor is performed on several types of one-dimensional slab material. This study aims to determine the properties of suitable materials as moderators in thermal reactors. Also shown are suitable materials as control rods and reflectors. Usually the properties of the material is determined based on the absorption and scattering cross section data, but in this study indicated the form of the attenuation factor pattern of neutron. This research was carried out by using a computational simulation with featuring a form of neutron attenuation factor pattern by using MATLAB software. The thickness of the material used in this study is $20 \mathrm{~cm}$. There are 10 types of materials used in this research. The materials are light water $\left(\mathrm{H}_{2} \mathrm{O}\right)$, heavy water $\left(\mathrm{D}_{2} \mathrm{O}\right)$, graphite $(\mathrm{C})$, berrilium $(\mathrm{Be})$, Boron $(\mathrm{B})$, hydrogen $(\mathrm{H})$, hellium $(\mathrm{He})$, natrium $(\mathrm{Na})$, iron $(F e)$ and deuterium (D). The cross section data of the materials used in this study is the total cross section data of the materials which is the sum of the absorption and scattering cross section. The results showed that based on the neutron attenuation factor pattern, the suitable materials as moderator and also reflector are light water $(\mathrm{H} 2 \mathrm{O})$, heavy water $(\mathrm{D} 2 \mathrm{O})$, graphite $(\mathrm{C})$ and beryllium $(\mathrm{Be})$. On the other hand, this research inform that the suitable material as control rod is boron $(B)$.

Keywords: Neutron attenuation factor, moderator, thermal reactor, total cross section

\section{PENDAHULUAN}

Listrik telah menjadi suatu kebutuhan yang penting pada saat ini dan digunakan dalam berbagai bidang seperti perindustrian, pertanian, serta dalam aktivitas sehari-sehari (Pioro, 2013). Setiap hari kebutuhan listrik terus meningkat, sedangkan ketersediaan sumber daya listrik yang banyak digunakan saat ini yang berasal dari bahan bakar fosil mulai menipis (Agung, 2013). Salah satu cara untuk mengatasi permasalahan tersebut adalah dengan mencari alternatif lain sebagai sumber daya listrik. Pembangkit Listrik Tenaga Nuklir (PLTN) menjadi salah satu alternatif yang potensial untuk dijadikan sumber daya listrik. PLTN memiliki beberapa keunggulan; pertama, nuklir ramah lingkungan karena tidak menghasilkan emisi zat berbahaya seperti logam berat contohnya $\mathrm{Cd}, \mathrm{Pb}, \mathrm{As}, \mathrm{Hg}$, dan $\mathrm{V}$, serta juga tidak menghasilkan $\mathrm{SO}_{2}, \mathrm{NO}_{\mathrm{x}}$, dan $\mathrm{CO}_{2}$. Kedua, nuklir sebagai sumber daya alami mempunyai potensi yang paling 
besar dalam penyediaan energi yang diperlukan dibandingkan sumber daya lainnya seperti air, gas, minyak, geotermal dan batubara. Selanjutnya, introduksi nuklir tidak perlu menunggu sampai sumber daya lainnya menipis (non-depletion strategy), selain itu penggunaan nuklir dalam jaringan listrik akan menjamin stabilitas harga dan penyediaan energi (Adiwardoyo, 1996).

PLTN merupakan sebuah sistem yang mempunyai beberapa bagian utama, yaitu reaktor, turbin, generator dan kondenser (Brain dan Lamb, 2000). Reaktor merupakan bagian paling penting dari sebuah sistem PLTN. Reaktor terdiri dari beberapa komponen utama, yaitu bahan bakar nuklir, moderator, reflektor, batang kendali dan perisai. Reaktor merupakan tempat terjadinya reaksi nuklir yaitu berupa reaksi fisi yang akan menghasilkan energi panas yang selanjutnya akan diubah menjadi energi listrik (Beiser, 1987). Reaksi fisi yang terjadi berasal dari proses pembelahan bahan fisil seperti atom ${ }^{235} \mathrm{U}$ yang disebabkan oleh penembakan neutron pada bahan tersebut. Hasil dari reaksi fisi berupa partikel inti yang lebih ringan (sering disebut produk fisil), beberapa partikel neutron, gelombang elektromagnetik dalam bentuk sinar gamma, dan sejumlah energi (BATAN, 2010).

Neutron bebas yang dihasilkan dari reaksi fisi merupakan bagian penting untuk keberlangsungan reaksi nuklir selanjutnya yang dikenal dengan istilah reaksi fisi berantai. Permasalahannya adalah neutron yang dihasilkan pada proses reaksi fisi nuklir yang pertama kali memiliki energi $1 \mathrm{MeV}-20 \mathrm{MeV}$ (fast neutron). Energi tersebut sangat besar sehingga sangat sulit digunakan untuk melakukan reaksi nuklir selanjutnya yang mengakibatkan reaksi rantai nuklir susah terjadi pada reaktor termal. Dalam reaksi fisi neutron yang dapat menyebabkan reaksi pembelahan adalah neutron termal (Mairing dan Prihatnadi, 2009). Cara yang bisa digunakan untuk mengatasi permasalahan tersebut adalah dengan menurunkan energi neutron. Energi tersebut harus dilemahkan sampai $0,025 \mathrm{eV}$ (thermal neutron). Proses pelemahan energi neutron dengan istilah neutron attenuation.

Pelemahan energi neutron pada reaktor dilakukan oleh moderator. Neutron berenergi tinggi dari hasil reaksi fisi nuklir akan mengalami perlambatan atau mengalami pengurangan energi setelah menumbuk bahan moderator.Tidak semua bahan bisa digunakan sebagai moderator karena ada beberapa syarat yang harus diperhatikan, seperti penampang lintang serapan harus kecil, penampang lintang hamburan harus besar, memiliki daya hantar panas yang baik serta tidak bersifat korosif (Mairing dan Prihatnadi, 2009). Salah satu bahan yang pertama kali digunakan sebagai moderator adalah grafit (C). Contoh reaktor yang menggunakan grafit sebagai moderator adalah reaktor RFT, serta beberapa reaktor yang ada di Uni Soviet dan Inggris (Goncharov, 1958). Selain grafit, ada juga reaktor yang menggunakan air ringan $\left(\mathrm{H}_{2} \mathrm{O}\right)$ dan air berat $\left(\mathrm{D}_{2} \mathrm{O}\right)$ sebagai bahan moderator. Nagi dkk. (2014) menyebutkan bahwa $\mathrm{H}_{2} \mathrm{O}$ merupakan bahan yang dikenal paling baik sebagai moderator, tapi cenderung memiliki nilai penampang lintang neutron tangkapan yang besar. Sedangkan jumlah penggunaan $\mathrm{D}_{2} \mathrm{O}$ sebagai moderator berada di bawah $\mathrm{H}_{2} \mathrm{O}$, namun bahan ini memiliki keuntungan yaitu nilai penampang lintang neutron tangkapannya yang rendah. Magan dkk. (2013) pernah melakukan pengamatan terhadap keefektifan penggunanan $\mathrm{H}_{2} \mathrm{O}, \mathrm{D}_{2} \mathrm{O}$ dan Be sebagai bahan moderator. Hasil yang ditemukan dalam penelitian tersebut adalah bahwa $\mathrm{H}_{2} \mathrm{O}$ dan $\mathrm{D}_{2} \mathrm{O}$ lebih efektif digunakan sebagai bahan moderator dibandingkan Be.

Selain moderator, reaktor juga memiliki komponen lain seperti reflektor. Neutron hasil reaksi fisi yang tidak menumbuk bahan moderator akan keluar dari sistem atau teras reaktor. Neutron yang keluar atau bocor ini, membutuhkan suatu media untuk kembali ke teras reaktor agar dapat digunakan untuk reaksi fisi selanjutnya. Media tersebut dikenal dengan reflektor. Bahan yang digunakan sebagai reflektor memiliki sifat yang sama dengan bahan yang digunakan sebagai moderator (Soentono, 1998). Selain moderator dan reflektor terdapat komponen reaktor yang disebut dengan batang kendali. Batang kendali mempunyai sifat yang berbeda dengan moderator dan reflektor. Batang kendali harus memiliki penampang lintang serapan yang besar, karena salah satu fungsi batang kendali adalah untuk menyerap neutron yang berlebih. Penyerapan neutron yang berlebih ini bertujuan untuk menghindari bahaya seperti ledakan. Dalam sistem PLTN, neutron dalam reaktor harus dikendalikan pada batasbatas tertentu agar sistem dapat berjalan dengan baik (Soentono, 1998). 
Penelitian ini menelaah tentang beberapa bahan yang paling efektif untuk dijadikan sebagai moderator dalam reaktor termal dengan memperlihatkan pola faktor pelemahan neutronnya. Selain itu ditunjukkan juga bahan yang cocok sebagai reflector dan batang kendali. Terdapat 10 bahan yang diteliti dalam penelitian ini, yaitu air ringan $\left(\mathrm{H}_{2} \mathrm{O}\right)$, air berat $\left(\mathrm{D}_{2} \mathrm{O}\right)$, grafit $(\mathrm{C})$, berilium $(\mathrm{Be})$, boron $(\mathrm{B})$, hidrogen $(\mathrm{H})$, helium $(\mathrm{He})$, natrium $(\mathrm{Na})$, besi $(\mathrm{Fe})$ dan deuterium (D). Pada penelitian ini diperlihatkan proses pelemahan neutron pada masing-masing bahan berbentuk slab satu dimensi dengan menggunakan MATLAB.

\section{METODE}

\subsection{Data}

Data yang digunakan dalam penelitian ini adalah data sifat fisik (massa jenis dan molaritas) dan data penampang lintang total (absorbsi dan hamburan) dari 10 bahan yang digunakan, yaitu $\mathrm{H}_{2} \mathrm{O}, \mathrm{D}_{2} \mathrm{O}, \mathrm{C}, \mathrm{Be}, \mathrm{B}, \mathrm{H}, \mathrm{He}, \mathrm{Na}, \mathrm{Fe}$ dan $\mathrm{D}$.

\subsection{Pengolahan Data}

Data sifat fisik dan penampang lintang dari 10 bahan yang diteliti diolah menggunakan aplikasi pengolahan data MATLAB 2015a. Langkah-langkah untuk melakukan perhitungan pada pelemahan neutron sebagai berikut :

1. Membuat masukan awal data perhitungan $N_{a}, \sigma_{t}, \rho, M, x, \Delta x$ yang telah ditentukan berdasarkan data yang telah ada.

2. Menghitung penampang lintang makroskopik $(\Sigma)$ menggunakan Persamaan (1) dan (2) untuk setiap moderator

$$
\begin{gathered}
N=\frac{N_{a} \rho}{A} \\
\Sigma=\sum N_{i x} \sigma_{i x}
\end{gathered}
$$

3. Menghitung attenuation factor menggunakan Persamaan (3) untuk setiap $\Delta x$ sejauh ketebalan moderator $x$.

$$
A F_{i}=\frac{I_{0}}{I}=e^{-\Sigma x_{i}}
$$

4. Plot grafik fraksi intensitas vs ketebalan moderator slab satu dimensi.

\section{HASIL DAN DISKUSI}

Simulasi faktor pelemahan neutron dalam reaktor termal yang menggunakan berbagai bahan berbentuk slab satu dimensi ini bertujuan untuk mengetahui bahan mana yang efektif untuk digunakan sebagai moderator, reflektor dan batang kendali dalam reaktor termal. Pada bagain ini dibahas keefektifan masing-masing bahan sebagai moderator berdasarkan syaratsyarat bahan moderator pada reaktor nuklir, yaitu dengan memperhatikan nilai penampang lintang serapan yang harus kecil, penampang lintang hamburan besar, nomor massa atom yang kecil, memiliki daya hantar panas yang baik serta tidak bersifat korosif.

Gambar 1 menunjukkan grafik pola faktor pelemahan energi neutron pada sepuluh bahan. Bahan yang efektif untuk digunakan sebagai moderator reaktor termal adalah bahan yang memiliki grafik dengan nilai fraksional intensitas paling cepat mendekati nol tapi tidak sampai benar-benar menyentuh titik nol. Hal ini dikarenakan jika nilai fraksional intensitas bernilai nol berarti energi neutron bukan dilemahkan melainkan diserap habis. Sedangkan tujuan dari moderator adalah untuk melemahkan energi neutron demi keberlangsungan reaksi fisi selanjutnya, jika energi neutron habis terserap maka tidak akan ada neutron untuk reaksi fisi selanjutnya. Berdasarkan grafik pada Gambar 1 terlihat bahwa boron (B) adalah unsur yang paling cepat nilai fraksional intensitasnya mendekati nol. Kemudian secara berurutan bahan 
moderator yang memiliki nilai fraksional intensitas paling cepat mendekati nol atau yang paling cepat melemahkan neutron adalah $\mathrm{H}_{2} \mathrm{O}, \mathrm{Fe}, \mathrm{Be}, \mathrm{C}, \mathrm{D}_{2} \mathrm{O}, \mathrm{Na}, \mathrm{H}, \mathrm{D}$ dan terakhir He. Namun, setelah meninjau syarat-syarat bahan moderator, terdapat bahan yang tidak efektif untuk dijadikan sebagai moderator, karena sifat moderator adalah sama dengan sifat reflektor, maka dalam penelitian ini bahan seperti $\mathrm{H}_{2} \mathrm{O}, \mathrm{D}_{2} \mathrm{O}, \mathrm{C}$ dan $\mathrm{Be}$ cocok digunakan sebagai moderator dan reflektor, sedangkan B cocok digunakan sebagai batang kendali. Keefektifan sepuluh bahan sebagai moderator reactor termal dibahas secara menyeluruh pada sub-bab berikut :

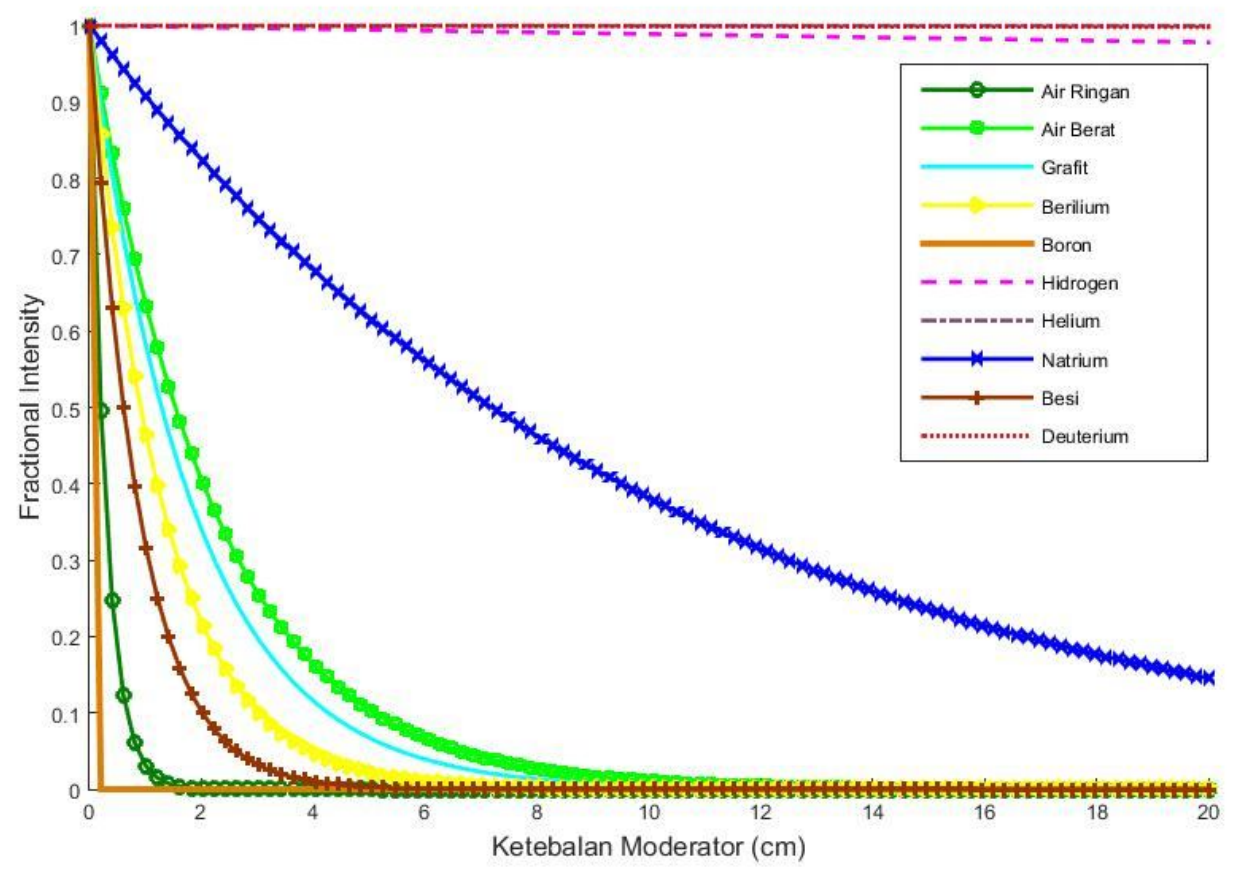

Gambar 1 Grafik faktor pelemahan neutron pada 10 bahan

\subsection{Air Ringan}

Grafik pada Gambar 1 menunjukkan nilai fraksional intensitas air ringan dengan ketebalan $20 \mathrm{~cm}$. Penggunaan air ringan sebagai bahan moderator dapat melemahkan neutron pada ketebalan moderator kurang $2 \mathrm{~cm}$. Berdasarkan grafik, bisa disimpulkan bahwa air ringan efektif digunakan sebagai bahan moderator, karena nilai fraksional intensitas yang cepat mendekati nol yang berarti pada moderator ini proses pelemahan neutron tidak membutuhkan waktu yang lama. Alasan lain yang mendukung air ringan dapat digunakan sebagai bahan moderator adalah nilai neutron cross section absorbtion adalah 0,664 barns. Nilai ini sangat kecil dibandingkan nilai neutron cross section scattering air ringan yang besar, yaitu 103 barns. Nilai $\sigma_{a}$ yang sangat kecil dan nilai $\sigma_{s}$ yang besar ini sesuai dengan syarat untuk bahan moderator.

\subsection{Air Berat}

Gambar 1 menunjukkan grafik fraksional intensitas moderator air berat yang ditunjukkan oleh garis berwarna hijau. Grafik pada Gambar 1 menunjukkan bahwa neutron melemah dan pelemahan mendekati nol setelah menumbuk bahan moderator sejauh $12 \mathrm{~cm}$. Berdasarkan syarat bahan moderator, dapat disimpulkan bahwa air berat dapat digunakan sebagai bahan moderator. Sama dengan air ringan yang telah dibahas pada sub-bab 3.1, air berat juga memiliki nilai $\sigma_{a}$ yang sangat kecil dibandingkan dengan nilai $\sigma_{s}$. Nilai $\sigma_{a}$ air berat adalah 0,00133 sedangkan nilai $\sigma_{s}$ nya adalah 13,6 , dimana jika dibandingkan nilai $\sigma_{a}$ dengan $\sigma_{s}$ maka nilainya adalah 1:10000. Meskipun memiliki nilai $\sigma_{a}$ yang lebih kecil dibanding dengan air ringan, penggunaan air berat sebagai moderator lebih lambat dalam melemahkan energi neutron. Hal ini dapat disebabkan oleh massa molekul relatif air berat yang lebih besar daripada 
air ringan. Selain itu, air ringan mempunyai daya hantar panas yang lebih baik daripada air berat.

\subsection{Grafit}

Grafit (C) sebagai bahan moderator sedikit lebih cepat melemahkan neutron dibandingkan dengan air berat, namun lebih lambat jika dibandingkan dengan air ringan seperti yang tampak pada Gambar 1. Fraksional intensitas grafit (C) mendekati nol setelah neutron mengalami tumbukkan dengan moderator sejauh $14 \mathrm{~cm}$. grafit (C) merupakan salah satu unsur dengan nomor massa 12 . Grafit memiliki nilai $\sigma_{a}$ dan $\sigma_{s}$ dengan perbandingan 1:1000, ini berarti sesuai dengan syarat bahan moderator yang harus memiliki nilai $\sigma_{a}$ kecil dan $\sigma_{s}$ besar. Selain itu, grafit (C) termasuk bahan yang memiliki daya hantar yang baik diantara bahan-bahan lainnya. Berdasarkan hal-hal tersebut grafit dapat dipertimbangkan untuk digunakan sebagai bahan moderator.

\subsection{Berilium}

Berilium (Be) lebih cepat melemahkan neutron dibandingkan dengan grafit, dimana intensitas fraksional sudah mendekati nol pada ketebalan $7 \mathrm{~cm}$. Hal ini dapat diliihat pada grafik di Gambar 1 yang bewarna kuning. Berilium (Be) merupakan unsur dengan nomor massa 9. Sama halnya dengan grafit (C), berilium (Be) juga memiliki perbandingan $\sigma_{a}$ dan $\sigma_{s}$ 1:1000. Namun, berilium memiliki nomor massa yang lebih kecil dari grafit, serta merupakan bahan yang memiliki daya hantar paling baik diantara bahan yang lainnya.

\subsection{Boron}

Boron adalah atom yang memiliki nomor massa 11. Dari sepuluh bahan yang diteliti, boron adalah bahan yang paling cepat dalam melemahkan neutron seperti yang terlihat pada Gambar 1. Gambar 1 menunjukkan nilai fraksional intensitas boron (B) yang langsung mengalami penurunan drastis sampai ke nilai nol. Pada sebuah moderator nilai intensitas ini tidak boleh sampai benar-benar nol. Hal ini terjadi karena nilai $\sigma_{a}$ boron paling tinggi diantara yang lainnya. Nilai $\sigma_{a}$ boron adalah satu-satunya yang jauh lebih besar dibandingkan nilai $\sigma_{s}$ nya. Nilai $\sigma_{a}$ boron merupakan satu-satunya yang bernilai ratusan. Hal inilah yang menyebabkan boron memiliki nilai fraksional intensitas paling cepat menuju nol, dikarenakan dalam penggunaan sebagai moderator boron lebih menyerap energi neutron daripada melemahkannya seperti yang terlihat pada grafik. Berdasarkan syarat bahan moderator, yaitu nilai $\sigma_{a}$ kecil dan $\sigma_{s}$ besar, maka Boron disimpulkan tidak efektif untuk dijadikan sebagai bahan moderator. Jika semua energi neutron diserap, maka tidak akan ada lagi neutron yang bisa digunakan untuk reaksi fisi selanjutnya. Namun, berdasarkan sifatnya tersebut, dapat disimpulkan bahwa boron (B) lebih cocok untuk dijadikan sebagai batang kendali pada suatu reaktor.

\subsection{Hidrogen}

Grafik faktor pelemahan neutron hidrogen pada Gambar 1 hanya sedikit terlihat penurunan intensitas fraksional dalam moderator $20 \mathrm{~cm}$. Pada ketebalan moderator $20 \mathrm{~cm}$, nilai intensitas fraksional masih berada pada 0,98. Meskipun memiliki nomor massa yang kecil, tetapi hidrogen memiliki nilai $\sigma_{a}$ yang lebih besar dari pada berilium, helium, grafit dan air berat. Selain itu, hidrogen yang berwujud gas memiliki daya hantar panas yang rendah dibandingkan dengan unsur-unsur yang telah dibahas sebelumnya. Selain itu, dengan memperhatikan pola faktor pelemahan neutron hydrogen tidak eksponensial, maka dapat disimpulkan bahwa hidrogen tidak cocok sebagai moderator.

\subsection{Helium}

Penggunaan helium sebagai bahan moderator bisa disimpulkan kurang efektif sama halnya dengan hidrogen. Hal ini terlihat dari grafik faktor pelemahan neutron menggunakan bahan helium yang tidak terlalu menurun pada intensitas fraksionalnya. Pada ketebalan moderator $20 \mathrm{~cm}$, nilai intensitas fraksional helium sebagai bahan moderator masih berada pada 
0,99 yang sangat mendekati 1 seperti yang terlihat pada Gambar 1. Helium merupakan bahan yang memiliki $\sigma_{s}$ paling kecil dibanding dengan bahan yang lainnya. Selain itu, seperti hidrogen, helium juga berwujud gas dan memiliki nilai daya hantar panas yang rendah, serta dengan memperhatikan pola faktor pelemahan neutron helium tidak eksponensial, maka dapat disimpulkan bahwa helium tidak cocok sebagai moderator.

\subsection{Natrium}

Gambar 1 menunjukkan penurunan nilai fraksional intensitas pada moderator dengan ketebalan $20 \mathrm{~cm}$ dengan natrium $(\mathrm{Na})$ sebagai bahannya. Fraksional intensitas masih berada pada nilai 0,2 ketika neutron telah menembus neutron setebal $20 \mathrm{~cm}$. Natrium termasuk salah satu bahan yang memiliki daya hantar yang baik. Namun, natrium memiliki perbandingan nilai $\sigma_{a}$ dan $\sigma_{s}$ yang tidak terlalu besar seperti air berat, sehingga hal ini bisa jadi menyebabkan lambatnya pelemahan energi neutron. Oleh karena itu natrium tidak efektif untuk dijadikan sebagai moderator. Natrium lebih cocok sebagai bahan pendingin pada reaktor cepat.

\subsection{Besi}

Besi merupakan bahan yang memiliki nomor massa paling besar dibandingkan dengan sembilan bahan lainnya. Garis bewarna cokelat muda pada Gambar 1 menunjukkan bagaimana penurunan intensitas fraksional terhadap moderator berketabalan $20 \mathrm{~cm}$ dengan bahan besi $(\mathrm{Fe})$. Besi termasuk bahan yang bisa melemahkan neutron dengan cepat, dimana nilai intensitas fraksionalnya sudah mendekati nol pada ketebalan $4 \mathrm{~cm}$. Besi merupakan bahan yang memiliki daya hantar yang baik diantara sepuluh bahan yang diuji sebagai moderator. Namun, besi memiliki perbandingan nilai $\sigma_{a}$ dan $\sigma_{s}$ yang tidak terlalu berbeda seperti halnya dengan natrium. Bahkan $\sigma_{a}$ besi merupakan yang terbesar nomor dua dibanding dengan yang lainnya. Namun sifat besi yang korosif memyebabkannya tidak efektif dijadikan sebagai moderator.

\subsection{Deuterium}

Deutrium merupakan unsur hidrogen dengan nomor massa 2. Pada Gambar 1, grafik pelemahan neutron dalam bahan moderator deuterium ditunjukkan oleh garis bewarna merah. Deuterium termasuk bahan yang lambat dalam melemahkan energi neutron. Pada ketebalan 20 $\mathrm{cm}$, nilai intensitas fraksionalnya berada pada titik 0,9982. Diantara sepuluh bahan yang diuji sebagai moderator, deuterium adalah bahan yang memiliki nilai $\sigma_{a}$ yang paling kecil, namun meskipun begitu deutrium menjadi bahan yang lambat dalam melemahkan neutron karena deuterium memiliki nilai $\sigma_{s}$ yang juga kecil. Selain itu, deutrium memiliki daya hantar panas yang paling rendah dibanding bahan lainnya. Dengan memperhatikan pola faktor pelemahan neutron deuterium tidak eksponensial, maka dapat disimpulkan bahwa deuterium tidak cocok sebagai moderator. Deuterium cocok sebagai moderator jika berekasi dengan oksigen menjadi air berat $\left(\mathrm{D}_{2} \mathrm{O}\right)$.

\section{KESIMPULAN}

Berdasarkan pengolahan data dan analisa yang telah dilakukan, maka dapat disimpulkan bahwa jenis bahan moderator yang paling efektif berdasarkan pola faktor pelemahan neutronnya dalam reaktor termal adalah air ringan $\left(\mathrm{H}_{2} \mathrm{O}\right)$, air berat $\left(\mathrm{D}_{2} \mathrm{O}\right)$, grafit $(\mathrm{C})$ dan berilium (Be). Mengingat sifat moderator adalah sama dengan sifat reflektor, maka bahanbahan tersebut cocok juga sebagai reflektor. Bahan berbentuk gas seperti hidrogen $(\mathrm{H})$, deuterium (D) dan helium (He) dapat dikatakan kurang efektif untuk dijadikan sebagai moderator karena proses pelemahan energi neutron yang lambat dan polanya tidak eksponensial. Besi (Fe) meskipun mempunyai pola pelemahan neutron dengan cepat, namun karena sifatnya yang korosif, besi $(\mathrm{Fe})$ tidak cocok sebagai moderator. Sedangkan natrium $(\mathrm{Na})$ merupakan bahan yang terlalu lambat dalam pelemahan neutron, oleh karena itu natrium tidak efektif untuk dijadikan sebagai moderator. Natrium lebih cocok sebagai bahan pendingin pada reactor cepat. Selanjutnya, terdapat satu bahan yang sebaiknya tidak digunakan sebagai moderator, yaitu boron (B), karena pola faktor pelemahan neutron Boron sangat cepat menyerap energi neutron sampai habis. Sifat ini dikarenakan boron (B) memiliki tampang lintang serapan 
$\left(\sigma_{a}\right)$ yang sangat besar dibandingkan bahan lainnya. Dengan sifat seperti itu boron (B) efektif bila digunakan sebagai batang kendali.

\section{DAFTAR PUSTAKA}

Adiwardoyo, 1996, Prospek PLTN dalam Penyediaan Energi Nasional, Prosiding Presentasi Ilmiah Daur Bahan Bakar Nuklir II, hal. 11-18.

Agung, A.I., 2013, Potensi Sumber Energi Alternatif dalam Mendukung Kelistrikan Nasional, Jurnal Pendidikan Teknik Elektro, Vol. 2, No. 2, hal. 892 - 897.

BATAN, 2010, Buku Pintar Nuklir, BATAN, Jakarta.

Beiser, Concept of Modern Physics (6 ${ }^{\text {th }}$ Edition), McGraw-Hill, New Delhi.

Gancharov, V.V., 1958, Graphite in Nuclear Reactor, Journal Nuclear Energy II, Vol. 7, pp. 115-124, London.

Magan, M., Sordo, F., Zanini, L., Terron, S., Ghiglino, A., Martinez, F., de Vicente, J.P., Vicanco, R., Perlado, J.M., Bermejo, F.J., Mezei, F., Muhrer, G., Neutronic Analysis of the bi-Spectral Moderator Such As That Proposed for ESS, Nuclear Instruments and Methods in Physics Research, Vol. A 729, pp. 417-425.

Mairing, MP., dan Prihatnadi, H., 2009, Tinjauan Bahan Moderator untuk Komponen Reaktor Nuklir, Jurnal Perangkat Nuklir, Vol. 03, hal. 49 - 54.

Nagi, M.E., Aly, M.N., Gaber, F.A., Dorrah, M.E., 2014, Neutronic Behaviour of reactor moderated by mixtures of light and heavy waters at different ratio, Annals of Nuclear Energy, Vol. 63, pp. 548-555.

Pioro, I., 2013, Nuclear Power as a Basic for Future Electricity Production in the World, Current Research in Nuclear Reactor Technology in Brazil and Worldwide, A.Z Mesquita and H. C. Rezende eds, INTECH, Rijeka, Croatia, pp. $211-250$.

Soentono, S., 1998, Bahan-Bahan untuk Industri Reaktor Nuklir, Prosiding Pertemuan Ilmiah Sains Materi III, Serpong.

Brain, M., dan Lamb, R., 2000, How Nuclear Power Works,

http://science.howstuffworks.com/nuclear-power.htm, diakses September 2017. 